\title{
Serotonin Syndrome in the Post-Anesthesia Care Unit after Remifentanil Infusion and Ondansetron: A Case Report and Literature Review
}

\author{
Andrea J Ibarra* and Li Meng \\ Department of Anesthesiology, University of Pittsburgh Medical Center, USA
}

Submission: February 02, 2018; Published: February 08, 2018

*Corresponding author: Andrea J Ibarra, Department of Anesthesiology, University of Pittsburgh Medical Center, 3550 Terrace St, Pittsburgh, PA 15213 USA, Tel: 347-601-6417; Email: ibarraaj@upmc.edu

\begin{abstract}
Serotonin syndrome (SS) is a clinical diagnosis with serious consequences if unrecognized. Medications that raise serotonin levels by enhancing its release or formation or inhibit its reuptake or breakdown increase the risk of SS, especially when multiple agents are used. This report describes the case of a 61-year-old-female who presented for a resection of a recurrent craniopharyngioma via an Endoscopic Endonasal Approach (EEA) and developed SS in the post-anesthesia care unit (PACU) after remifentanil infusion and ondansetron in the setting of escitalopram. Relevant literature describing risk factors, diagnosis and treatment is reviewed.
\end{abstract}

Keywords: Serotonin syndrome; Remifentanil; PACU; Escitalopram; Ondansetron

Abbreviations: SS: Serotonin Syndrome; MAOIs: Monoamine Oxidase Inhibitors; SSRIs: Selective Serotonin Reuptake Inhibitors; PONV: PostOperative Nausea and Vomiting; OR: Operating Room; NICU: Neuro-Intensive Care Unit FDA: Food and Drug Administration

\section{Introduction}

Serotonin syndrome (SS) presents as a spectrum of symptoms including neuromuscular hyperactivity, altered mental status and autonomic changes and is frequently associated with medications such as monoamine oxidase inhibitors (MAOIs) and selective serotonin reuptake inhibitors (SSRIs) [1]. Antidepressants (e.g. SSRIs) are among the twenty most frequently prescribed outpatient medications [2] and therefore are commonly encountered in surgical patients. Other common perioperatively encountered proserotonergic drugs are opioid analgesics and antiemetics. Concomitant use of multiple proserotonergic drugs increases the risk of SS. SS has been reported after fentanyl and ondansetron exposure in patients taking SSRIs and MAOIs; however, the interaction between remifentanil and ondansetron has not been described before. This case describes SS after remifentanil infusion and ondansetron after an EEA procedure.

\section{Case Description}

Written informed consent was obtained from the patient for this report. A 62-year-old female presented for a recurrent craniopharyngioma resection via EEA procedure. Pertinent medical history includes pan-hypopituitarism, post-operative nausea and vomiting (PONV), anxiety and depression. Relevant home medications listed the day of surgery are escitalopram $10 \mathrm{mg}$ daily and rizatriptan $10 \mathrm{mg}$ twice per day as needed.
Preoperatively she received aprepitant $40 \mathrm{mg}$ and no anxiolytics. A pre-induction arterial line was placed. Intraoperatively, general anesthesia was accomplished with rocuronium $5 \mathrm{mg}$ for de-fasciculation, succinylcholine $180 \mathrm{mg}$, propofol 200mg, dexmedetomidine $8 \mathrm{mcg}$ and $16 \mathrm{mcg}$ with 7 -minute interval and remifentanil infusion at $0.02 \mathrm{mcg} / \mathrm{kg} / \mathrm{min}$.

Intubation and ventilation through an end tracheal tube followed. After induction, norepinephrine infusion was started at $0.04 \mathrm{mcg} / \mathrm{kg} / \mathrm{min}$ for hypotension that eventually improved with surgical stimuli. Sevoflurane and remifentanil infusion were used for maintenance of anesthesia and intermittent doses of rocuronium were given for paralysis. Intraoperatively, blood pressure was variable with systolic pressures ranging from 120 to $170 \mathrm{mmHg}$ and diastolic pressures from 60 to $90 \mathrm{mmHg}$. Ephedrine and phenylephrine boluses were given for hypotension. Skin temperature averaged $350 \mathrm{C}$ with a lower body forced air warming device in place. End tidal $\mathrm{CO} 2$ ranged from 25 to $35 \mathrm{mmHg}$. At the end of the three-hour procedure, the remifentanil infusion was stopped 20 minutes before leaving the operating room (OR) and 4 mg of ondansetron was administered 5 minutes thereafter. Trainof-four elicited 4/4 twitches and neuromuscular blockade was antagonized with neostigmine $5 \mathrm{mg}$ and glycopyrrolate $0.8 \mathrm{mg} 5$ minutes after ondansetron was given. The endotracheal tube was removed when the patient met extubation criteria the last arterial blood pressure measured in the OR was $151 / 70 \mathrm{mmHg}$. 
On the way to the PACU, patient was noted to have lower extremity clonus. The first vital signs were 163/90 mmHg, heart rate $68 \mathrm{BPM}$, and SpO2 100\% on 6 liters nasal cannula upon arrival to the PACU. Fifteen minutes later, the patient developed hypertension to $189 / 94 \mathrm{mmHg}$ measured by noninvasive cuff, as well as shivering and nausea. She was treated with hydralazine $10 \mathrm{mg}$ twice, promethazine $12.5 \mathrm{mg}$ once and a forced-air warming blanket. She did not report pain or required analgesics. The patient also exhibited confusion, diaphoresis and mydriasis. Her hypertension and nausea improved after giving the medications. An emergent computed tomography of the head without contrast was performed to evaluate for acute intracranial processes and showed only expected postoperative changes. Two hours later, she developed a fever of $38.8^{\circ} \mathrm{C}$, tachycardia up to $128 \mathrm{BPM}$, and tachypnea up to 29 respirations per minute as well as a headache. She was treated with $1 \mathrm{~g}$ of acetaminophen and $0.4 \mathrm{mg}$ of hydromorphone. Her urine output increased to 1.2 liters over 2 hours. She received $0.5 \mathrm{mg}$ of desmopressin to treat presumed diabetes insipidus. Her symptoms progressively abated approximately eight hours after surgery. The patient was transferred to the neuro-intensive care unit (NICU) for further monitoring. She was discharged home on post-operative day 3 without sequela.

\section{Discussion}

Serotonin syndrome (SS) is a rare condition that, if unrecognized, can become life threatening. More than $85 \%$ of general practitioners have reported unawareness of the syndrome [3] yet medical providers' ability to diagnose clinical symptoms is key to institute timely therapy and avoid poor outcome. The onset of symptoms occurs within six hours of exposure and typically resolves within 24 hours after stopping the precipitating agents $[1,2]$. High index of suspicion and careful physical examination are essential because no laboratory test can help confirm the presence of SS. Diagnosis is based on Hunter criteria (84\% sensitivity, 97\% specificity) among patients taking serotonergic agents (Table 1) [4]. Symptoms range from mild cases with only autonomic findings including shivering, diaphoresis or mydriasis, to moderate with hypertension, tachycardia, hyperthermia and lower extremity clonus, to severe with severe hypertension, fever $(>41.1 \mathrm{oC})$, acute respiratory distress, rhabdomyolysis, renal failure, coma and death.

Table 1: Hunter Criteria for diagnosis of Serotonin Syndrome [4].

\begin{tabular}{|l|}
\hline One or more serotonergic agents and one of the following: \\
\hline Spontaneous clonus \\
\hline Inducible clonus and agitation or diaphoresis \\
\hline Ocular clonus and agitation or diaphoresis \\
\hline Tremor and hyperreflexia \\
\hline $\begin{array}{l}\text { Hypertonia and temperature }>380 \mathrm{C} \text { and ocular clonus or inducible } \\
\text { clonus }\end{array}$ \\
\hline
\end{tabular}

This case fulfilled the Hunter Criteria with the following symptoms: spontaneous lower extremity clonus, agitation, diaphoresis and fever in the presence of several proserotonergic medications. Other pertinent symptoms include mydriasis, shivering, hypertension and tachycardia. This presentation falls into the moderate SS spectrum and did not require treatment escalation. The possible offending agents include escitalopram, ondansetron, remifentanil, and rizatriptan. In the presence of serotonergic medications such as SSRIs or tryptans, further administration of intraoperative proserotonergic agents can precipitate SS (Table 2). The role of escitalopram precipitating SS is supported by its mechanism of action and its mean terminal half-life of 27 to 32 hours, making it likely that a relevant plasma concentration was present the day of surgery.

Table 2: Common proserotonergic medications used intraoperatively.

\begin{tabular}{|c|c|}
\hline Anti-emetics & Opioids \\
\hline Ondansetron & Fentanyl \\
\hline Metoclopramide & Meperidine \\
\hline & Tramadol \\
\hline Antibiotics & Sufentanil \\
\hline Linezolid & Alfentanil \\
\hline & Methadone \\
\hline Dyes & Buprenorphine \\
\hline Methylene blue & Remifentanil \\
\hline
\end{tabular}

US Food and Drug Administration (FDA) list ondansetron as a serotonergic medication. It is hypothesized that in the presence of serotonergic agents, ondansetron increases the levels of serotonin by antagonizing 5-HT3 and may result in increased 5-HT1A stimulation. Gollapudy et al reported a case of SS in a patient taking paroxetine, duloxetine and bupropion in the setting of fentanyl and ondansetron that required intubation in the PACU [5]. Remifentanil is not a known serotonergic medication. However, fentanyl is the most common phenylpiperidine opioid presented in SS case reports because it is a known 5-HT1A agonist capable of increasing serotonin release and weakly blocking its reuptake [6]. Hyper stimulation of 5-HT1A and 5-HT2A has been associated with the development of SS. The beneficial effects of SS antidote, cyproheptadine, a 5-HT2A antagonist corroborate these findings. Remifentanil is also a member of the phenylpiperidine family with a rapid onset and recovery time. By belonging to the phenylpiperidine family, remifentanil could potentially share the same proserotonergic properties, causing an increase of serotonin levels at the post-synaptic cleft enough to precipitate SS despite its relatively short context-sensitive half-life. Because onset of symptoms in our case was 20 minutes after stopping remifentanil infusion, it is possible that it contributed to SS development.

Rizatriptan is a direct serotonin agonist with high affinity for 5-HT1B/5-HT1D and lower affinity for 5-HT1A and a shorter halflife of 2 to 3 hours. Our patient took this medication on as needed basis. Even if the last dose was the day of surgery, it is likely that plasma concentration was not significant when the symptoms developed. In addition, although the FDA warns that the combined use of trip tans and SSRIs may increase risk of SS, this warning is based on 29 SS cases that on recent review did not fulfill the 
Hunter Criteria $[7,8]$ Rizatriptan therefore does not appear to be the culprit in this case of SS.

The differential diagnosis for this case includes neuroleptic malignant syndrome, malignant hyperthermia and anticholinergic syndrome. Neuroleptic malignant syndrome (NMS) usually is associated with slower onset and resolution, occurs in the context of dopamine antagonist administration and presents with signs of "lead pipe" rigidity [9] Malignant hyperthermia (MH) is characterized by higher temperature (up to $114.8 \mathrm{oF} / 46 \mathrm{oC}$ ) after exposure to a volatile agent or succinylcholine with rigor-mortis like rigidity and increasing concentrations of ETCO2 [10]. The patient did not show signs of rigidity but rather clonus and there was no intraoperative increase of ETC02, severe fever or relevant MH history. Anticholinergic syndrome and SS can present with pyrexia, tachycardia, confusion hypertension and tachycardia. Even though, the patient received promethazine her diaphoresis and clonus differentiate SS from anticholinergic syndrome.

Intraoperative recognition of SS is challenging as general anesthesia obliterate patient feedback and neuromuscular blocking agents can mask the clonus limiting early SS recognition. Anesthesiologists must conduct a thorough preoperative evaluation of patients at risk of SS to reduce morbidity and mortality. While the incidence of perioperative SS is very low or under-represented, its consequences can be lethal, especially with delay in treatment. It is critically important that potential proserotonergic properties of commonly intraoperative medications are widely known. Having a list of medications in the OR could be helpful to consider other anesthetic techniques without proserotonergic properties (e.g morphine and its analogs) to avoid life-threatening interactions, if concern for SS is high. Remifentanil, much like fentanyl, and ondasentron can contribute to the development of SS; however further studies are necessary to confirm this association and elucidate the exact mechanism.

\section{Acknowledgement}

We thank Dr. Jurgis Alvikas and Dr. Tetsuro Sakai for their assistance with proof reading and suggestions.

\section{Conflicts of Interest}

None.

\section{References}

1. Boyer EW, Shannon M (2005) The serotonin syndrome. N Engl J Med 352(11): 1112-1120.

2. Cherry DK, Hing E, Woodwell DA, Rechtsteiner EA (2008) National Ambulatory Medical Care Survey: 2006 summary. Natl Health Stat Report (3): 1-39.

3. Mackay FJ, Dunn NR, Mann RD (1999) Antidepressants and the serotonin syndrome in general practice. Br J Gen Pract 49(448): 871874.

4. Dunkley EJC, Isbister GK, Sibbritt D, Dawson AH, Whyte IM (2003) The Hunter Serotonin Toxicity Criteria: simple and accurate diagnostic decision rules for serotonin toxicity. QJM 96(9): 635-642.

5. Gollapudy S, Kumar V, Dhamee MS (2012) A case of serotonin syndrome precipitated by fentanyl and ondansetron in a patient receiving paroxetine, duloxetine, and bupropion. J Clin Anesth 24(3): 251-252.

6. Gillman PK (2006) A review of serotonin toxicity data: implications for the mechanisms of antidepressant drug action. Biol Psychiatry 59(11): 1046-1051.

7. FDA Alert (2006) Combined Use of 5-Hydroxytryptamine Receptor Agonists (Triptans), Selective Serotonin Reuptake Inhibitors (SSRIs) or Selective Serotonin/Norepinephrine Reuptake Inhibitors (SNRIs) May Result in Life-threatening Serotonin Syndrome.

8. Evans RW, Tepper SJ, Shapiro RE, Sun Edelstein C, Tietjen GE (2010) The FDA alert on serotonin syndrome with use of triptans combined with selective serotonin reuptake inhibitors or selective serotoninnorepinephrine reuptake inhibitors: American Headache Society position paper. Headache 50(6): 1089-1099.

9. Guze BH, Baxter LRJ (1985) Current concepts. Neuroleptic malignant syndrome. N Engl J Med 313(3): 163-166.

10. Ali SZ, Taguchi A, Rosenberg H (2003) Malignant hyperthermia. Best Pract Res Clin Anaesthesiol 17(4): 519-533.

\section{Your next submission with Juniper Publishers will reach you the below assets}

- Quality Editorial service

- Swift Peer Review

- Reprints availability

- E-prints Service

- Manuscript Podcast for convenient understanding

- Global attainment for your research

- Manuscript accessibility in different formats

( Pdf, E-pub, Full Text, Audio)

- Unceasing customer service

Track the below URL for one-step submission

https://juniperpublishers.com/online-submission.php 